\title{
OPEN
}
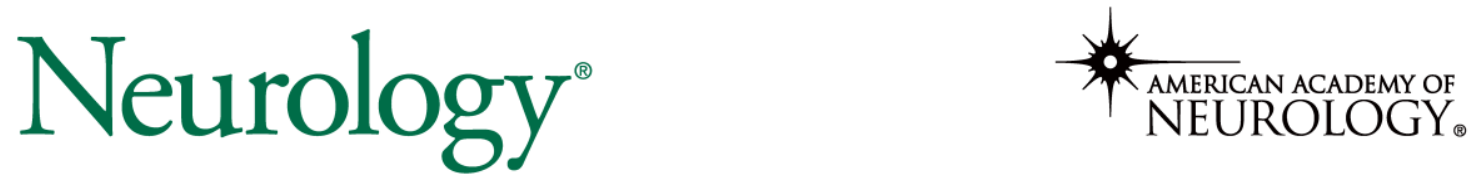

The most widely read and highly cited peer-reviewed neurology journal

The Official Journal of the American Academy of Neurology

Neurology Publish Ahead of Print

DOI: 10.1212/WNL.0000000000200051

\section{Cognitive Reserve and Mild Cognitive Impairment: Predictors and Rates of Reversion to Intact Cognition vs Progression to Dementia}

Author(s):

Maryam Iraniparast, $\mathrm{PhD}^{1}$; Yidan Shi, $\mathrm{PhD}^{2}$; Ying Wu, $\mathrm{PhD}^{2,3}$; Leilei Zeng, $\mathrm{PhD}^{2}$; Colleen J Maxwell, $\mathrm{PhD}^{1,4}$; Richard J Kryscio, $\mathrm{PhD}^{5,6,7}$; Philip D St. John, MD ${ }^{8,9}$; Karen S SantaCruz, MD ${ }^{10}$; Suzanne L Tyas, $\mathrm{PhD}^{1}$

This is an open access article distributed under the terms of the Creative Commons AttributionNonCommercial-NoDerivatives License 4.0 (CC BY-NC-ND), which permits downloading and sharing the work provided it is properly cited. The work cannot be changed in any way or used commercially without permission from the journal.

Neurology ${ }^{\circledR}$ Published Ahead of Print articles have been peer reviewed and accepted for publication. This manuscript will be published in its final form after copyediting, page composition, and review of proofs. Errors that could affect the content may be corrected during these processes. 


\section{Corresponding Author:}

Suzanne L Tyas

styas@uwaterloo.ca

Affiliation Information for All Authors: 1. School of Public Health Sciences, University of Waterloo, Waterloo, ON, Canada; 2. Department of Statistics and Actuarial Science, University of Waterloo, Waterloo, ON, Canada; 3. School of Statistics and Data Science, Nankai University, Tianjin, China; 4. School of Pharmacy, University of Waterloo, Waterloo, ON, Canada; 5. Department of Statistics, University of Kentucky, Lexington, KY, USA; 6. Department of Biostatistics, University of Kentucky, Lexington, KY, USA; 7. Sanders-Brown Center on Aging, University of Kentucky, Lexington, KY, USA; 8. Department of Medicine, Section of Geriatric Medicine, Max Rady College of Medicine, University of Manitoba, Winnipeg, MB, Canada; 9. Centre on Aging, University of Manitoba, Winnipeg, MB, Canada; 10. Department of Laboratory Medicine and Pathology, University of New Mexico School of Medicine, Albuquerque, NM, USA

\section{Contributions:}

Maryam Iraniparast: Drafting/revision of the manuscript for content, including medical writing for content; Study concept or design; Analysis or interpretation of data; Additional contributions: conducted the literature search Yidan Shi: Drafting/revision of the manuscript for content, including medical writing for content; Analysis or interpretation of data

Ying Wu: Drafting/revision of the manuscript for content, including medical writing for content; Analysis or interpretation of data

Leilei Zeng: Drafting/revision of the manuscript for content, including medical writing for content; Study concept or design; Analysis or interpretation of data

Colleen J Maxwell: Drafting/revision of the manuscript for content, including medical writing for content; Study concept or design; Analysis or interpretation of data

Richard J Kryscio: Drafting/revision of the manuscript for content, including medical writing for content; Analysis or interpretation of data

Philip D St. John: Drafting/revision of the manuscript for content, including medical writing for content Karen S SantaCruz: Drafting/revision of the manuscript for content, including medical writing for content Suzanne L Tyas: Drafting/revision of the manuscript for content, including medical writing for content; Study concept or design; Analysis or interpretation of data

Number of characters in title: 116

Abstract Word count: 348

Word count of main text: 4334 
Figures: 1

Tables: 6

Supplemental: 1. eAppendix 2. Revised manuscript with highlighted changes3. STROBE reporting guidelines

Search Terms: [ 25 ] All Cognitive Disorders/Dementia, [ 39 ] MCI (mild cognitive impairment), [ 59 ] Risk factors in epidemiology

Study Funding: This study was funded by Canadian Institutes of Health Research (CIHR) operating grant 137035 to SLT, and Natural Sciences and Engineering Research Council of Canada (NSERC) discovery grant RGPIN115928 to LZ. Funding for the Nun Study at the University of Kentucky was provided by the U.S. National Institute of Aging (R01AG09862, K04AG00553, P50AG05144) and the Kleberg Foundation and, for interpretation of statistical modelling, by R01AG038651 to RJK.

Disclosures: M. Iraniparast reports no disclosures relevant to the manuscript; Y. Shi reports no disclosures relevant to the manuscript; Y. Wu reports no disclosures relevant to the manuscript; L. Zeng reports no disclosures relevant to the manuscript; C. J. Maxwell reports no disclosures relevant to the manuscript; R. J. Kryscio reports no disclosures relevant to the manuscript; P. D. St. John reports financial relationships for contractual clinical and administrative activities (Winnipeg Regional Health Authority and Shared Services Manitoba), and serving as a speaker (University of Ottawa/Regional Geriatric Program of Eastern Ontario) and board member (Meals on Wheels (Manitoba), Age and Opportunity); K. S. SantaCruz reports no disclosures relevant to the manuscript; S. L. Tyas reports no disclosures relevant to the manuscript. 


\section{Abstract}

Background and Objectives: Little is known about the effect of education or other indicators of cognitive reserve on the rate of reversion from mild cognitive impairment (MCI) to normal cognition (NC), or the relative rate of reversion from MCI to NC vs. progression from MCI to dementia. Our objectives were to: 1) estimate transition rates from MCI to NC and dementia, and 2) determine the effect of age, apolipoprotein E (APOE), and indicators of cognitive reserve on the relative rate (RR) of reversion vs. progression using multistate Markov modelling.

Methods: We estimated instantaneous transition rates between NC, MCI and dementia after accounting for transition to death across up to 12 assessments in the Nun Study, a cohort study of religious sisters aged $75+$ years. We estimated RRs of reversion vs. progression for age, APOE, and potential cognitive reserve indicators: education, academic performance (high school grades), and written language skills (idea density, grammatical complexity).

Results: Of the 619 participants, 472 were assessed with MCI during the study period. Of these $472,143(30.3 \%)$ experienced at least one reverse transition to NC, and 120 of the $143(83.9 \%)$ never developed dementia (mean follow-up=8.6 years). In models adjusted for age group and $A P O E$, higher levels of education more than doubled the RR ratio of reversion vs. progression. Novel cognitive reserve indicators were significantly associated with a higher adjusted RR of reversion vs. progression (higher vs. lower levels for English grades: RR Ratio $=1.83$; idea density: $\mathrm{RR}$ ratio=3.93; and grammatical complexity: $\mathrm{RR}$ ratio=5.78).

Discussion: Knowledge of frequent reversion from MCI to NC may alleviate concerns of inevitable cognitive decline in those with MCI. Identification of characteristics predicting the 
rate of reversion from MCI to NC vs. progression from MCI to dementia may guide populationlevel interventions targeting these characteristics to prevent or postpone MCI and dementia. Research on cognitive trajectories would benefit from incorporating predictors of reverse transitions and competing events, such as death, into statistical modelling. Finally, these results may inform the design and interpretation of MCI clinical trials, given that a substantial proportion of participants may experience improvement without intervention. 


\section{Introduction}

Cognition is fluid, and cognitive states can improve or decline over time. Individuals with mild cognitive impairment (MCI) typically progress to dementia, but some instead revert to normal cognition (NC). ${ }^{1-4}$ Determining the rate of transition from MCI to NC, comparing rates of reversion (MCI to NC) to progression (MCI to dementia), and identifying predictors associated with these transitions is important to inform the clinical prognosis of individuals with MCI and the design and interpretation of MCI clinical trials, and to develop public health strategies to prevent or delay dementia.

Little is known about the effect of education or other indicators of cognitive reserve on the rate of reversion from $\mathrm{MCI}$ to $\mathrm{NC}$, or the relative rate of reversion from $\mathrm{MCI}$ to $\mathrm{NC}$ vs. progression from MCI to dementia. Younger age ${ }^{5,6}$ and absence of an apolipoprotein E (APOE)- $\varepsilon 4$ allele ${ }^{6-9}$ have been reported to be significantly associated with reversion from MCI to NC, whereas results for education are inconsistent. ${ }^{5,6,10}$ However, none of these risk factor studies accounted for transitions to dementia and to death despite the fact that these competing transitions are common in older adults.

Our aims were to: 1) jointly model the instantaneous rates of reversion from MCI to NC and progression from MCI to dementia while considering transitions from MCI to death; and 2) determine the effect of age, $A P O E$, and indicators of cognitive reserve (educational attainment, academic performance and written language skills) on the relative transition rate of reversion vs. progression. 


\section{Methods}

\section{Study Sample}

The methodology of the Nun Study has previously been described. ${ }^{11}$ In brief, it is a longitudinal study of aging and cognition among members of a religious congregation (the School Sisters of Notre Dame) living in the United States. Participants were all women with similar adult lifestyles, including socioeconomic status, social support, marital and reproductive histories, alcohol and tobacco use, and access to health services. Of 1,031 eligible religious sisters aged 75 years or older at baseline (1991-1993), 678 agreed to participate, and their mean age, race, death rate, and country of birth did not differ significantly from nonparticipants. ${ }^{11}$ Cognitive function was assessed at baseline and approximately annually thereafter, until death or the end of the 12th round of assessments. The analytic sample was restricted to participants with post-baseline data (i.e., at least one follow-up cognitive assessment or date of death), and data on APOE status and education ( $\mathrm{n}=619)$. For a subset of participants, data from convent archives were available on academic performance (course grades for English, $n=454$; Latin, $n=416$; algebra, $n=451$; geometry, $\mathrm{n}=435$ ) and written language skills (idea density, $\mathrm{n}=164$; grammatical complexity, $\mathrm{n}=164)$.

\section{Measures}

\section{$\underline{\text { Cognitive states }}$}

The diagnostic criteria for NC, MCI, and dementia applied at each assessment have been described previously ${ }^{12}$ and are summarized briefly below. Cognitive performance in the Nun Study was assessed using five measures from the Consortium to Establish a Registry for Alzheimer's Disease (CERAD) neuropsychological battery: ${ }^{13}$ 
Delayed Word Recall, Verbal Fluency, Boston Naming, Constructional Praxis, and the Minimental State Exam (MMSE). Cut points on these tests for NC, MCI and dementia were based on CERAD normative data, ${ }^{12,14}$ which included women with comparable age and education to those of the Nun Study. ${ }^{12}$

Normal cognition: Criteria for NC were based on intact cognition in the Delayed Word Recall ( $\geq 5$ ), Boston Naming $(\geq 14)$, Verbal Fluency $(\geq 12)$ and Constructional Praxis $(\geq 9)$ tests; intact global cognition based on the MMSE $(\geq 24) ;{ }^{15}$ and intact function in activities of daily living ${ }^{16}$ (feeding, dressing, walking, standing [transferring], and toileting), defined as the ability to independently complete at least four of the five activities.

Mild cognitive impairment: Individuals with $\mathrm{MCI}$ did not meet criteria for $\mathrm{NC}$ or dementia. They had at least one specific area of impaired cognitive function, with cut points for impairment at 1.5 SD below age-appropriate means (Delayed Word Recall $<5$, Boston Naming $<14$, Verbal Fluency $<12$, and Constructional Praxis $<9$ ). They could also be impaired in global cognitive ability (MMSE $<24)$ or activities of daily living; however, they did not meet criteria for dementia because if more than one area of cognition was impaired, they were intact in activities of daily living. This cognitive state reflects all cognitive impairment states less severe than dementia (previously described in Riley et al. ${ }^{12}$ ).

Dementia: Participants were diagnosed with dementia based on the presence of an impairment in memory and in at least one other cognitive domain. For dementia, impairment was identified based on performance below the fifth percentile of CERAD normative data: ${ }^{14}$ Delayed Word Recall $<4$, Boston Naming $<13$, Verbal Fluency $<11$, and Constructional Praxis $<8$, functional impairment in activities of daily living, and decline from a previous level of cognitive function. ${ }^{12}$ 


\section{$\underline{\text { Predictors }}$}

Genotyping of $A P O E$ was performed according to standard methods ${ }^{17}$ and blinded to cognitive status. Convent archival records provided data on age, educational attainment and academic performance in first-year high school courses (English, Latin, algebra, and geometry), which was extracted from high school transcripts listing courses and grades achieved. Measures of written language skills (idea density and grammatical complexity) were based on handwritten autobiographies from the convent archives and have previously been described. ${ }^{11}$ In brief, these autobiographies were written at a mean age of 22 years $(\mathrm{SD}=2.9)$ before entering the religious order, and provided a summary of life events. The last ten sentences of each autobiography were coded to yield mean scores for idea density and grammatical complexity, which were ranked within each convent. Scores for idea density were based on the mean number of ideas expressed per ten words, while scores for grammatical complexity on an 8-level scale were based on the Developmental Level metric. ${ }^{11,18-20}$

\section{Statistical Analysis}

Multistate Markov models were used to estimate the instantaneous rates of transition between three transient cognitive states -- NC (state 0), MCI (state 1) and dementia (state 2) -- and one absorbing state, death (state 3) (Figure 1). Transitions were treated as reversible between NC and MCI, and unidirectional between other states (i.e., non-reversible from dementia and MCI, as well as from death to any cognitive state).

The Markov assumption is most commonly adopted in multistate models for which the transition rates only depend on the current state and time, and not the full history of past transitions. Multistate Markov models in continuous time are formulated by specifying transition intensity 
functions, the instantaneous rate of making one of these transitions given the individual is at risk of such a transition at a given time point. Let $\lambda_{j k}(t)$ denote the intensity for the state $j$ to state $k$ transition at age $t$; then, $\lambda_{01}(t)$ indicates the intensity for the transition from state 0 to state 1 $(\mathrm{NC} \rightarrow \mathrm{MCI})$ while $\lambda_{10}(t)$ indicates the intensity for the reverse transition from state 1 to state 0 $(\mathrm{MCI} \rightarrow \mathrm{NC}), \lambda_{12}(t)$ represents the transition rate from MCI to dementia, and $\lambda_{03}(t), \lambda_{13}(t)$ and $\lambda_{23}(t)$ are mortality intensities for individuals with NC, MCI, and dementia respectively.

Covariates are associated with the transition intensities based on the proportional intensity model (similar to the Cox proportional hazard model in survival analysis for a single event) such that $\lambda_{j k}(t)=\lambda_{j k 0}(t) e^{X^{T} \beta_{j k}}$, where $\mathrm{X}$ is the vector of covariates (age, $A P O E-\varepsilon 4$, education, academic performance and written language skills); $\boldsymbol{\beta}_{j k}$ represents the covariate effects that differ from one transition to another; and $\lambda_{j k 0}(t)$ represents the baseline transition rate with a piecewiseconstant structure, that is, $\lambda_{\mathrm{jkl}}(t)=\alpha_{j k l}$ for age category 1 . Conditional on the initial state, the likelihood function was constructed based on the multistate Markov model with mixed types of panel observation for cognitive status (observed at prespecified times) and death (upon occurrence). The $m s m$ package for $\mathrm{R}^{21}$ was used for fitting continuous-time Markov multistate models with piecewise-constant transition intensities to longitudinal data.

Age is the time scale, motivated by knowledge that the risk of MCI, dementia, and death depends on age, after assuming piecewise constant transition rates within each of the age intervals (75-90 and $90+$ years). The baseline intensity $\lambda_{j k 0}(t)$ depends on time/age. We initially used a piecewise constant model to categorize age $t$ by five-year age groups $[75,80),[80,85),[85,90)$, $[90,95)$ and $\geq 95$ such that $\lambda_{j k 0}(t)=\alpha_{j k l}$ when $t$ falls in the $l$ th age interval, $l=1,2, \ldots, 5$. The final model used 90 years as the sole breakpoint given that assessment of the transition 
intensities between cognitive states for different five-year age groups showed that the transition rates were more similar for those 90 years and younger compared to those above 90 years of age.

Three sets of analyses were conducted by fitting different multistate Markov models for transition intensities: 1) piecewise-constant baseline transition rates without adjusting for covariates; 2) piecewise-constant baseline intensities and multiplicative effects of APOE; and 3) piecewise-constant baseline rates and multiplicative effects of $A P O E$ and each indicator of cognitive reserve (education, academic performance, or written language skills). Note that the effect of each cognitive reserve indicator was evaluated separately to determine its effects independent of other indicators while controlling for the effects of age and APOE- $\varepsilon 4$ status. We report the corresponding measures from the above analyses: 1) unadjusted baseline age-specific transition rates; 2) the relative transition rate (RR), defined as the ratio of the reverse transition rate from $\mathrm{MCI}$ to $\mathrm{NC}$ to the progression transition rate from MCI to dementia, by age group and APOE- $\varepsilon 4$ status; 3 ) RRs by different levels of the cognitive reserve indicators, age group and APOE- 84 status; and 4) the ratios of RRs, reflecting the impact of the cognitive reserve indicator on the $\mathrm{RR}$ of reversion vs. progression, adjusted for age group and $A P O E-\varepsilon 4$ status. Here the ratio of RRs reduces to $\exp \left(\beta_{10}-\beta_{12}\right)$ where $\beta_{1 \mathrm{j}}$ is the beta coefficient associated with a specific cognitive indicator variable and is defined free of age. Additional statistical details are provided in eAppendix 1. The R code for data analysis is available upon request from YS.

\section{Standard Protocol Approvals, Registrations, and Patient Consents}

Ethics approval by institutional review boards was obtained from the University of Kentucky for the original Nun Study and from the University of Waterloo for the current study.

\section{Data Availability}


The data used in this article will be made available by the corresponding author to qualified investigators upon reasonable request.

\section{Results}

\section{Sample Description}

Participants were all older women who were 75 years or older at baseline $(14.5 \%>90$ years) and were generally highly educated $(84.5 \%$ with an undergraduate or graduate degree) (Table 1$)$. This high level of intellectual achievement was also reflected in strong academic performance across all four high school courses. Among the 619 participants, 472 were observed to have MCI at some point during the follow-up period, and $143(30.3 \%)$ of these showed at least one reverse transition from MCI to NC. These 143 participants were followed for an average of 8.6 years $(\mathrm{SD}=4.1)$ after their first diagnosis of $\mathrm{MCI} ; 120(83.9 \%)$ never developed dementia over an average of 8.6 years of follow-up, with 34 of these 120 participants remaining cognitively intact after reverting from MCI to NC. Another 142 participants progressed to dementia after a diagnosis of MCI without a reverse transition to NC, 16 remained in the MCI state until the end of the follow-up period, and 171 progressed to death without reversion to $\mathrm{NC}$ or progression to dementia. No participant reverted to MCI from dementia.

\section{Unadjusted Age-specific Transition Rates}

The reverse transition rate from MCI to NC dropped from 0.15 per year $(95 \% \mathrm{CI}=0.13-0.18)$ in participants $\leq 90$ years to 0.07 per year $(95 \% \mathrm{CI}=0.05-0.11)$ in participants $>90$ years (Table 2$)$. The transition rate from MCI to death more than doubled across age groups, increasing from $0.07(95 \% \mathrm{CI}=0.05-0.08)$ in participants $\leq 90$ years to $0.15(95 \% \mathrm{CI}=0.12-0.20)$ in those $>90$ years. The risks of transition from MCI to death, dementia, and NC were $0.07,0.07$, and 0.15 
respectively in participants $\leq 90$ years compared to $0.17,0.15$, and 0.07 respectively in participants over 90 years of age. That is, for those 90 years or younger, the risks of death and dementia were similar, but reversion to $\mathrm{NC}$ was more common. For those over 90 years of age, the risks of death and dementia were similar, but reversion to NC was less common.

\section{RRs by Age Group and $A P O E$}

The proportion of participants with an $A P O E-\varepsilon 4$ allele (carriers) was similar across age groups at baseline: of the 529 participants $<=90$ years, $119(22 \%)$ were $A P O E-\varepsilon 4$ carriers compared to 22 (24\%) of the 90 participants $>90$ years. Those 529 participants $<=90$ years at baseline provided information on transitions in cognitive status prior to 90 years of age. There were 371 participants (75 APOE- $\varepsilon 4$ carriers and $295 A P O E-\varepsilon 4$ noncarriers) who survived to have data collected after the age of 90 , and they contributed to the estimation of transition rates beyond age 90.

Among participants $\leq 90$ years, $A P O E-\varepsilon 4$ noncarriers showed almost triple the rate of reversion from MCI to NC than progression from MCI to dementia $(\mathrm{RR}=2.93,95 \% \mathrm{CI}=2.18-3.92)$; in contrast, this was not observed in $A P O E-\varepsilon 4$ carriers $(\mathrm{RR}=0.68,95 \% \mathrm{CI}=0.38-1.21)$ (Table 3$)$. Participants $>90$ years were more likely to progress to dementia from MCI than to revert to NC regardless of $A P O E-\varepsilon 4$ status. However, $A P O E-\varepsilon 4$ status remained influential, with these older $A P O E-\varepsilon 4$ noncarriers more than four times $(0.47 / 0.11)$ as likely as older $A P O E-\varepsilon 4$ carriers to revert from MCI to NC rather than progress from MCI to dementia (Table 3).

\section{RRs by Cognitive Reserve Indicator, Age Group, and $A P O E$}

The impact of cognitive reserve indicators on reversion from MCI to NC vs. progression from MCI to dementia was assessed for education, academic performance, and written language skills 
separately. In models of education by age and APOE, APOE- 4 noncarriers $\leq 90$ years remained more likely to revert than progress from MCI only if they had attained a Bachelor's degree or higher (Table 4). In contrast, progression was significantly more likely than reversion regardless of educational level for those over 90 years of age, as well as for $A P O E$ - $\varepsilon 4$ carriers $\leq 90$ years with a high school or lower level of education.

In models of academic performance, across all levels and courses, reversion continued to be significantly more likely than progression for $A P O E-\varepsilon 4$ noncarriers $\leq 90$ years, whereas progression was significantly more likely than reversion for $A P O E-\varepsilon 4$ carriers over 90 years of age (Table 5). Examining course-specific effects, for $A P O E-\varepsilon 4$ noncarriers $>90$ years, progression was significantly more likely than reversion regardless of performance levels in algebra and geometry; however, this held only for the lower performance level for English and Latin. English showed the strongest effects of any of the courses: APOE-\&4 noncarriers $\leq 90$ years with higher performance in English had the highest chance of reversion vs. progression $(\mathrm{RR}=4.79,95 \% \mathrm{CI}=2.86-8.05)$, while $A P O E-\varepsilon 4$ carriers $>90$ years with lower performance in English showed the lowest chance $(\mathrm{RR}=0.07,95 \% \mathrm{CI}=0.03-0.18)$ (Table 5).

Models of idea density and grammatical complexity showed similar patterns of significance across both of these measures of written language skills. In APOE- $\varepsilon 4$ noncarriers $\leq 90$ years, reversion was significantly greater than progression for those with higher levels of these skills, whereas among $A P O E-\varepsilon 4$ carriers $>90$ years, progression was significantly greater than reversion for those with lower levels (Table 5).

\section{RR Ratios for Cognitive Reserve Indicators Adjusted for Age Group and APOE}


For each cognitive reserve indicator, the ratio of RRs by indicator level was used as a measure of its impact on the RR of reversion vs. progression in models adjusted for age group and APOE (Table 6). Compared to those with only a grade school or high school education, participants with a Bachelor's degree had more than double (RR ratio $=2.60 ; 95 \% \mathrm{CI}=1.05-6.45)$ and those with a Master's degree or higher had triple ( $\mathrm{RR}$ ratio $=2.94 ; 95 \% \mathrm{CI}=1.27-7.22)$ the $\mathrm{RR}$ of reversion vs. progression. Higher levels of performance in English and written language skills were associated with a significantly higher RR of reversion vs. progression (higher vs. lower levels for English grades: RR Ratio $=1.83,95 \% \mathrm{CI}=1.07-3.14$; idea density: $\mathrm{RR}$ ratio=3.93, 95\% CI=1.30-11.92; and grammatical complexity: $\mathrm{RR}$ ratio=5.78, 95\% CI=1.56-21.42) (Table 6).

\section{Discussion}

In this highly educated cohort of older religious sisters, reverse transitions from MCI to NC were relatively common and as frequent as transitions from MCI to dementia. The relatively younger age group ( $\leq 90$ years) and absence of an $A P O E-\varepsilon 4$ allele (i.e., lack of established risk factors for dementia) contributed to a significantly higher transition rate of reversion from MCI to NC vs. progression from MCI to dementia. Higher educational attainment, the traditional indicator of cognitive reserve, was associated with a significantly higher RR of reversion vs. progression compared to lower educational attainment. A similar statistically significant association was also found for novel indicators of cognitive reserve: academic performance in high school English, and written language skills (idea density and grammatical complexity).

This is the first study to our knowledge to demonstrate that those with higher levels of cognitive reserve indicators (educational attainment, academic performance, and written language skills) had a significantly greater chance of reversion from MCI to $\mathrm{NC}$ than progression from $\mathrm{MCI}$ to 
dementia. However, the observed association is consistent with literature on risk factors for dementia. ${ }^{7}$ Low educational attainment is a well-established risk factor for dementia. Although educational levels are generally higher for participants of the Nun Study than for other women of their era given greater educational opportunities through their religious order, the established association between lower education and higher risk of dementia is also found in the Nun Study. ${ }^{22}$ In addition, interactions between age, $A P O E$, and education have previously been shown in a subset of the Nun Study, with the highest risk of developing dementia among older APOE- $\varepsilon 4$ carriers with low levels of education. ${ }^{23}$ The protective effect of education on reversion from MCI to NC in this study is also consistent with findings from other cohorts of less educated men and women. ${ }^{7}$ The association between higher educational attainment and lower risk of dementia has traditionally been attributed to cognitive reserve ${ }^{24}$ and this link has been supported by evidence from imaging studies. ${ }^{25}$ However, in addition to a reduced risk of dementia, cognitive reserve may also have impacts on other cognitive outcomes, such as reversion from MCI to NC, through mechanisms such as neural compensation, whereby the brain creates compensatory paths to overcome the primary neural changes that lead to MCI. ${ }^{24}$

While education is the classic proxy for cognitive reserve, other intellectual factors may also predict reversion. Although less studied, higher academic performance has been associated with a lower risk of developing dementia. ${ }^{26-29}$ Intellectual aptitude in adolescence, including measures of word function in sentences and reading comprehension, has been associated with a reduced risk of Alzheimer's disease.$^{30}$ Early research based on an initial sample of decedents from the Nun Study showed that lower levels of idea density and grammatical complexity were associated with low cognitive test scores in late life and higher risk of Alzheimer's disease. ${ }^{11}$ In our larger sample of Nun Study participants, higher idea density and grammatical complexity, in addition 
to higher educational level and stronger academic performance in high school English, were associated with a greater chance of reversion from MCI to NC than progression from MCI to dementia. While our results show the importance of academic performance and written language skills as predictors of reversion, they also support the importance of education, a more widely available measure. The observed impact of all of these indicators of cognitive reserve has implications for population-level intervention strategies in early life to prevent or postpone MCI and dementia.

Our findings that almost one-third of participants revert from MCI to NC is consistent with previous reports on the proportion of such reverse transitions in other community settings and populations. $^{1,2,7,31}$ In their systematic review and meta-analysis, Canevelli and colleagues ${ }^{1}$ concluded that reversion to NC is common in individuals with MCI but is understudied. The studies that have been conducted on reversion from MCI have typically used standard Cox survival analysis, which does not adjust for competing transitions from MCI to dementia or from MCI to death. ${ }^{32,33}$ The use of survival analysis makes the assumption that individuals who experience a transition to dementia or death have the same rate of reversion from MCI to NC as those who remain and are included in the calculation of this reversion (i.e., that those censored are representative of those remaining). ${ }^{34,35}$ However, this assumption is questionable, and ignoring these competing effects of dementia and death may lead to biased estimates of the rate of reversion. ${ }^{34,36,37}$ Other analytic methods, such as binary logistic regression ${ }^{5}$ or generalized linear mixed modelling ${ }^{6}$ have also been used, but these are discrete time models looking at the probability of reversion and similarly have failed to account for transitions from MCI to dementia and to death. 
The use of multistate modelling addresses these analytic limitations and is a strength of our study. Multistate Markov models can account for competing events ${ }^{38}$ and are increasingly being used to study disease onset, progression and comorbidities in chronic diseases, including dementia. ${ }^{23,36,39-42}$ Our multistate models jointly estimated the instantaneous risks of transitions between cognitive states and transition to death, where transitions from MCI to dementia and to death were considered as competing events in the transition from MCI to NC. This joint modelling is particularly useful for studying older adults for whom transitions from MCI to dementia and death can occur at appreciable rates.

Other strengths included the analysis of data from a population-based longitudinal study that included up to 12 cognitive assessments and information on early-life intellectual factors. In addition, our Nun Study participants are uniquely homogeneous on many sociodemographic and lifestyle factors as well as access to health care, providing strong control of potential confounders. In contrast to clinical populations where cognitive changes can precipitate assessments, cognitive assessments in the Nun Study occurred at regularly scheduled intervals unrelated to cognitive status. In addition to the availability of extensive follow-up data with low attrition, these characteristics of the Nun Study data enabled the use of sophisticated modelling approaches. Further, data on novel hypothesized indicators of cognitive reserve (academic performance and written language skills) allowed exploration of factors beyond highest level of education attained, the standard proxy indicator for cognitive reserve. Future research could further investigate the impact of these and other intellectual measures in addition to educational level, such as through linkage studies of educational system and health administrative data.

A limitation of this and other studies of cognitive state transitions is that the exact time of transitions between states is not known. Because assessment is not continuous, unobserved 
transitions may occur and could, for example, lead to a loss of estimation efficiency for reverse transition from MCI to NC. In addition, cognition is fluid, and while transitions in cognitive states may reflect cognitive reserve, they may also reflect normal variation over time or acute factors influencing cognition. Improvement in cognition across assessments may also reflect regression to the mean or practice effects.

Diagnostic criteria evolve and this cannot be reflected in data already collected, a particular issue for longitudinal studies. Thus, cognitive states were diagnosed according to established criteria at baseline and criteria remained consistent to allow valid comparisons over time. Diagnostic criteria for MCI in particular have evolved, and thus our criteria, based solely on cognitive tests, may be more likely to reflect a transient MCI state than MCI diagnosed using additional information, such as from informant reports. $\mathrm{MCI}$ is a heterogeneous cognitive state, and we did not analyze subtypes of MCI (e.g., amnestic vs non-amnestic, single vs multiple-domain). There may be multiple reasons, including intervening medical states, for an individual to be classified with MCI, and these factors may influence transitions between states. We have limited data on some of the potential factors that may cause fluctuations in cognition. We also did not assess the neuropathologic substrate of MCI although it affects the clinical progression of MCI, with those progressing to dementia significantly more likely than those reverting to intact cognition to show severe Alzheimer neuropathology (neurofibrillary tangles, neuritic plaques) as well as other pathologic changes (e.g., hippocampal sclerosis of aging, Lewy Body disease). ${ }^{43}$

The sampling frame of the Nun Study is both a strength and a limitation. Generally speaking, population-based studies appear to show lower conversion rates to dementia and more variable trajectories. In clinical settings, the diagnosis of MCI is usually determined by clinical assessment, often using standardized assessments combined with clinical judgement. As well, the 
populations studied in clinical settings may be younger, healthier, and more homogeneous than those of population-based studies; clinical samples also present with symptoms for which they are seeking help. Thus, our findings need to be replicated in clinical settings.

While our modelling approach accounted for diverse age groups and cognitive states at baseline, it cannot address the impacts of potential survival bias on sampling. The Nun Study participants are not representative of the general population of older women in the United States, and analyses are based on data collected more than a decade ago; the results of this study thus need to be interpreted accordingly. Data on academic performance and written language skills were not available for all participants. Finally, despite the strengths of Markov modelling, this approach has some limitations. For example, the transition rate of reversion from MCI to NC may depend on the time since diagnosis of MCI, but Markov models do not incorporate the duration in each cognitive state.

Replication of the observed indicators of cognitive reserve in other populations as well as other factors influencing transitions across cognitive states, and in particular reverse transitions from MCI to NC, will help to better understand cognitive reserve and its impact on cognitive trajectories. Further development of analytic methods (e.g., adjusting multistate modelling to reduce the impact of survivor bias in longitudinal studies of aging) is needed to address current limitations. Knowledge of predictors of reversion from MCI to $\mathrm{NC}$ is important to inform the design and interpretation of clinical trials, given that a substantial proportion of participants may experience improvement from MCI to NC even without intervention. Evidence of predictors of these reverse transitions may also inform population-level intervention strategies targeting these characteristics to prevent or postpone $\mathrm{MCI}$ and dementia. 


\section{Appendix 1: Authors}

Name

Location

Contribution

\begin{tabular}{|c|c|c|}
\hline $\begin{array}{l}\text { Maryam Iraniparast, } \\
\mathrm{PhD}\end{array}$ & $\begin{array}{l}\text { University of } \\
\text { Waterloo, Waterloo, } \\
\text { Canada }\end{array}$ & $\begin{array}{l}\text { Designed the study; conducted the } \\
\text { literature search; interpreted the } \\
\text { analyses; wrote the initial draft; } \\
\text { critically reviewed the manuscript }\end{array}$ \\
\hline Yidan Shi, PhD & $\begin{array}{l}\text { University of } \\
\text { Waterloo, Waterloo, } \\
\text { Canada }\end{array}$ & $\begin{array}{l}\text { Developed and conducted the } \\
\text { analyses; wrote the initial draft of the } \\
\text { statistical analysis section; contributed } \\
\text { to the initial draft of the results } \\
\text { section; helped to create the tables and } \\
\text { figures; revised the manuscript for } \\
\text { intellectual content }\end{array}$ \\
\hline Ying $\mathrm{Wu}, \mathrm{PhD}$ & $\begin{array}{l}\text { Waterloo, Waterloo, } \\
\text { Canada; Nankai } \\
\text { University, Tianjin, } \\
\text { China }\end{array}$ & $\begin{array}{l}\text { Developed and conducted the } \\
\text { analyses; revised the manuscript for } \\
\text { intellectual content }\end{array}$ \\
\hline Leilei Zeng & $\begin{array}{l}\text { University of } \\
\text { Waterloo, Waterloo, } \\
\text { Canada }\end{array}$ & $\begin{array}{l}\text { Designed the study; designed the } \\
\text { statistical methods for analysis; wrote } \\
\text { the initial draft of the statistical } \\
\text { analysis section; contributed to the } \\
\text { initial draft of the results section; } \\
\text { interpreted the analyses; revised the } \\
\text { manuscript for intellectual content }\end{array}$ \\
\hline $\begin{array}{l}\text { Colleen J Maxwell, } \\
\text { PhD }\end{array}$ & $\begin{array}{l}\text { University of } \\
\text { Waterloo, Waterloo, } \\
\text { Canada }\end{array}$ & $\begin{array}{l}\text { Designed the study; interpreted the } \\
\text { analyses; revised the manuscript for } \\
\text { intellectual content }\end{array}$ \\
\hline Richard J Kryscio, $\mathrm{PhD}$ & University of & Interpreted the analyses; contributed \\
\hline
\end{tabular}


Kentucky, Lexington, to writing the results section; revised USA the manuscript for intellectual content

Philip D St. John, MD

University of Manitoba, Winnipeg, Canada

Revised the manuscript for intellectual content

University of New Mexico, Albuquerque, USA

Revised the manuscript for intellectual content

MD

University of

Provided the initial idea and funding for the study; designed the study;

Suzanne L. Tyas, PhD Waterloo, Waterloo, interpreted the analyses; wrote the Canada initial draft; critically reviewed the manuscript

Supplement -- http://links.lww.com/WNL/B774 


\section{REFERENCES}

1. Canevelli M, Grande G, Lacorte E, et al. Spontaneous reversion of mild cognitive impairment to normal cognition: a systematic review of literature and meta-analysis. J Am Med Dir Assoc 2016;17:943-948.

2. Malek-Ahmadi M. Reversion from mild cognitive impairment to normal cognition: a metaanalysis. Alzheimer Dis Assoc Disord 2016;30:324-330.

3. Petersen RC, Stevens JC, Ganguli M, Tangalos EG, Cummings JL, DeKosky ST. Practice parameter: early detection of dementia: mild cognitive impairment (an evidence-based review). Report of the quality standards subcommittee of the American Academy of Neurology. Neurology 2001;56:1133-1142.

4. Shimada H, Makizako H, Doi T, Lee S, Lee S. Conversion and reversion rates in Japanese older people with mild cognitive impairment. J Am Med Dir Assoc 2017;18:808.e1-808.e6.

5. Gao Q, Gwee X, Feng L, et al. Mild cognitive impairment reversion and progression: rates and predictors in community-living older persons in the Singapore Longitudinal Ageing Studies cohort. Dement Geriatr Cogn Dis Extra 2018;8:226-237.

6. Hadjichrysanthou C, McRae-McKee K, Evans S, de Wolf F, Anderson RM, Alzheimer's Disease Neuroimaging Initiative. Potential factors associated with cognitive improvement of individuals diagnosed with mild cognitive impairment or dementia in longitudinal studies. J Alzheimers Dis 2018;66:587-600. 
7. Xue H, Hou P, Li Y, Mao X, Wu L, Liu Y. Factors for predicting reversion from mild cognitive impairment to normal cognition: a meta-analysis. Int J Geriatr Psychiatry 2019;34:1361-1368.

8. Koepsell TD, Monsell SE. Reversion from mild cognitive impairment to normal or nearnormal cognition: risk factors and prognosis. Neurology 2012;79:1591-1598.

9. Pandya SY, Lacritz LH, Weiner MF, Deschner M, Woon FL. Predictors of reversion from mild cognitive impairment to normal cognition. Dement Geriatr Cogn Disord 2017;43:204-214.

10. Sachdev PS, Lipnicki DM, Crawford J, et al. Factors predicting reversion from mild cognitive impairment to normal cognitive functioning: a population-based study. PLoS One 2013;8:e59649.

11. Snowdon DA, Kemper SJ, Mortimer JA, Greiner LH, Wekstein DR, Markesbery WR. Linguistic ability in early life and cognitive function and Alzheimer's disease in late life: findings from the Nun Study. JAMA 1996;275:528-532.

12. Riley KP, Snowdon DA, Markesbery WR. Alzheimer's neurofibrillary pathology and the spectrum of cognitive function: findings from the Nun Study. Ann Neurol 2002;51:567-577.

13. Morris JC, Heyman A, Mohs RC, et al. The Consortium to Establish a Registry for Alzheimer's disease (CERAD): I. Clinical and neuropsychological assessment of Alzheimer's disease. Neurology 1989;39:1159-1165. 
14. Welsh KA, Butters N, Mohs RC, et al. The Consortium to Establish a Registry for Alzheimer's Disease (CERAD). Part V. A normative study of the neuropsychological battery. Neurology 1994;44:609-14.

15. Folstein MF, Folstein SE, McHugh PR. "Mini-mental state". A practical method for grading the cognitive state of patients for the clinician. J Psychiatr Res 1975;12:189-198.

16. Kuriansky J, Gurland B. The performance test of activities of daily living. Int J Aging Human Dev 1976;7:343-352.

17. Saunders AM, Hulette C, Welsh-Bohmer KA, et al. Specificity, sensitivity, and predictive value of apolipoprotein-E genotyping for sporadic Alzheimer's disease. Lancet 1996;348:90-93.

18. Cheung H, Kemper S. Competing complexity metrics and adults' production of complex sentences. Appl Psycholinguist 1992;13:53-76.

19. Kintsch W, Keenan J. Reading rate and retention as a function of the number of propositions in the base structure of sentences. Cognit Psychol 1973;5:257-274.

20. Turner A, Greene E. The construction and use of a propositional text base. Boulder: Institute for the Study of Intellectual Behavior, University of Colorado; 1977.

21. Jackson C. Multi-state models for panel data: the msm package for R. J Stat Softw 2011;38.

22. Mortimer JA, Snowdon DA, Markesbery WR. Head circumference, education and risk of dementia: findings from the Nun Study. J Clin Exp Neuropsychol 2003;25:671-679. 
23. Tyas SL, Salazar JC, Snowdon DA, et al. Transitions to mild cognitive impairments, dementia, and death: findings from the Nun Study. Am J Epidemiol 2007;165:1231-1238.

24. Stern Y. Cognitive reserve in ageing and Alzheimer's disease. Lancet Neurol 2012;11:10061012.

25. Lavretsky H. Resilience and aging: research and practice. Baltimore: Johns Hopkins University Press; 2014.

26. Mehta KM, Stewart AL, Langa KM, et al. "Below average" self-assessed school performance and Alzheimer's disease in the Aging, Demographics, and Memory Study. Alzheimers Dement 2009;5:380-387.

27. Bezerra ABC, Coutinho ESF, Barca ML, Engedal K, Engelhardt E, Laks J. School attainment in childhood is an independent risk factor of dementia in late life: results from a Brazilian sample. Int Psychogeriatr 2012;24:55-61.

28. Dekhtyar S, Wang H, Fratiglioni L, Herlitz A. Childhood school performance, education and occupational complexity: a life-course study of dementia in the Kungsholmen project. Int J Epidemiol 2016;45:1207-1215.

29. Dekhtyar S, Wang HX, Scott K, Goodman A, Koupil I, Herlitz A. A life-course study of cognitive reserve in dementia--from childhood to old age. Am J Geriatr Psychiatry 2015;23:885896.

30. Huang AR, Strombotne KL, Horner E, Lapham SJ. Adolescent cognitive aptitudes and laterin-life Alzheimer disease and related disorders. JAMA Netw Open 2018;1:e181626. 
31. Abner EL, Kryscio RJ, Cooper GE, et al. Mild cognitive impairment: statistical models of transition using longitudinal clinical data. Int J Alzheimers Dis 2012;2012:291920.

32. Roberts RO, Knopman DS, Mielke MM, et al. Higher risk of progression to dementia in mild cognitive impairment cases who revert to normal. Neurology 2014;82:317-325.

33. Grande G, Cucumo V, Cova I, et al. Reversible mild cognitive impairment: the role of comorbidities at baseline evaluation. J Alzheimers Dis 2016;51:57-67.

34. Murphy TE, Han L, Allore HG, Peduzzi PN, Gill TM, Lin H. Treatment of death in the analysis of longitudinal studies of gerontological outcomes. J Gerontol A Biol Sci Med Sci 2011;66:109-114.

35. Andersen PK, Geskus RB, de Witte T, Putter H. Competing risks in epidemiology: possibilities and pitfalls. Int J Epidemiol 2012;41:861-870.

36. Kryscio RJ, Abner EL, Lin Y, et al. Adjusting for mortality when identifying risk factors for transitions to mild cognitive impairment and dementia. J Alzheimers Dis 2013;35:823-832.

37. Crowder MJ. Multivariate survival analysis and competing risks. Boca Raton: CRC Press; 2012.

38. Cook RJ, Lawless JF. Multistate models for the analysis of life history data. Boca Raton: CRC Press; 2018.

39. Commenges D, Joly P, Letenneur L, Dartigues JF. Incidence and mortality of Alzheimer's disease or dementia using an illness-death model. Stat Med 2004;23:199-210. 
40. Sharples LD. Use of the Gibbs sampler to estimate transition rates between grades of coronary disease following cardiac transplantation. Stat Med 1993;12:1155-1169.

41. Xu J, Kalbfleisch JD, Tai B. Statistical analysis of illness-death processes and semicompeting risks data. Biometrics 2010;66:716-725.

42. Chen HH, Duffy DW, Tabar L, Day NE. Markov chain models for progression of breast cancer. Part I: tumour attributes and the preclinical screen-detectable phase. J Epidemiol Biostat 1997;2:9-23.

43. Abner EL, Kryscio RJ, Schmitt FA, et al. Outcomes after diagnosis of mild cognitive impairment in a large autopsy series. Ann Neurol 2017;81(4):549-459. 
Table 1: Sample characteristics, Nun Study

\begin{tabular}{|c|c|c|c|c|}
\hline & & Total sample & Ever diagnc & with MCI \\
\hline & & & Yes & No \\
\hline Characteristics & & $\mathrm{n}^{\mathrm{a}}(\%)$ & $\mathrm{n}^{\mathrm{a}}(\%)$ & $\mathrm{n}^{\mathrm{a}}(\%)$ \\
\hline Age at baseline & & & & \\
\hline & 75-90 years & $529(85.5 \%)$ & $426(90.3 \%)$ & $103(70.1 \%)$ \\
\hline & $>90$ years & $90(14.5 \%)$ & $46(9.7 \%)$ & $44(29.9 \%)$ \\
\hline$A P O E-\varepsilon 4$ allele & & & & \\
\hline & Noncarrier & $478(77.2 \%)$ & $382(80.9 \%)$ & $96(65.3 \%)$ \\
\hline & Carrier & $141(22.8 \%)$ & $90(19.1 \%)$ & $51(34.7 \%)$ \\
\hline Education & & & & \\
\hline & $\leq$ High school & $96(15.5 \%)$ & $54(11.4 \%)$ & $42(28.6 \%)$ \\
\hline & Bachelor's degree & $252(40.7 \%)$ & $196(41.5 \%)$ & $56(38.1 \%)$ \\
\hline & $\geq$ Master' & $271(43.8 \%)$ & $222(47.0 \%)$ & $49(33.3 \%)$ \\
\hline Academic Performance $^{b}$ & & & & \\
\hline English & Higher & $147(32.4 \%)$ & $108(30.4 \%)$ & $39(39.4 \%)$ \\
\hline & Lower & $307(67.6 \%)$ & $247(69.6 \%)$ & $60(60.6 \%)$ \\
\hline Latin & Higher & $185(44.5 \%)$ & $141(43.1 \%)$ & $44(49.4 \%)$ \\
\hline & Lower & $231(55.5 \%)$ & $186(56.9 \%)$ & $45(50.6 \%)$ \\
\hline Algebra & Higher & $185(41.0 \%)$ & $149(42.1 \%)$ & $36(37.1 \%)$ \\
\hline & Lower & $266(59.0 \%)$ & $205(57.9 \%)$ & $61(62.9 \%)$ \\
\hline Geometry & Higher & $173(39.8 \%)$ & $133(38.9 \%)$ & $40(43.0 \%)$ \\
\hline & Lower & $262(60.2 \%)$ & $209(61.1 \%)$ & $53(57.0 \%)$ \\
\hline Written Language Skills ${ }^{c}$ & & & & \\
\hline Idea density & Higher & $127(77.4 \%)$ & $111(84.1 \%)$ & $16(50.0 \%)$ \\
\hline & Lower & $37(22.6 \%)$ & $21(15.9 \%)$ & $16(50.0 \%)$ \\
\hline Grammatical complexity & Higher & $123(75.0 \%)$ & $106(80.3 \%)$ & $17(53.1 \%)$ \\
\hline & Lower & $41(25.0 \%)$ & $26(19.7 \%)$ & $15(46.9 \%)$ \\
\hline
\end{tabular}


Abbreviations: $A P O E-\varepsilon 4$ allele $=$ presence of an apolipoprotein $\mathrm{E}-\varepsilon 4$ allele; Carrier $=$ carries at least one APOE- $\varepsilon 4$

${ }^{\text {a }}$ Sample size is based on the number of participants with complete data on characteristics in multivariable analyses: $n=619$ except for academic performance (English n=454, Latin n=416, algebra n=451, geometry $\mathrm{n}=435)$ and written language skills $(\mathrm{n}=164)$

${ }^{\mathrm{b}}$ Higher academic performance (grade $>90 \%$ ) vs. lower (grade $\leq 90 \%$ )

${ }^{c}$ Higher written language skills (quartiles 2 to 4 ) vs. lower (quartile 1) 
Table 2: Transition rates across cognitive states by age based on a piecewise-constant ${ }^{\mathrm{a}}$ multistate Markov model $(\mathrm{n}=619)$

Age $\leq 90$

Transitions Between Cognitive

\begin{tabular}{lcc} 
States & Transition Rate $(\mathbf{9 5} \%$ CI) & Transition Rate (95\% CI) \\
\hline NC to MCI & $0.28(0.24-0.32)$ & $0.45(0.34-0.60)$ \\
NC to Death & $0.03(0.02-0.05)$ & $0.10(0.06-0.20)$ \\
MCI to NC & $0.15(0.13-0.18)$ & $0.07(0.05-0.11)$ \\
MCI to Dementia & $0.07(0.06-0.09)$ & $0.17(0.13-0.21)$ \\
MCI to Death & $0.07(0.05-0.08)$ & $0.15(0.12-0.20)$ \\
Dementia to Death & $0.19(0.16-0.23)$ & $0.41(0.36-0.47)$
\end{tabular}

Abbreviations: $\mathrm{MCI}=$ mild cognitive impairment; $\mathrm{NC}=$ normal cognition

${ }^{\mathrm{a}}$ Breakpoint is age 90 
Table 3: Relative transition rate of reversion from MCI to normal cognition vs. progression from MCI to dementia by age and $A P O E-\varepsilon 4$ status using a piecewise-constant ${ }^{\mathrm{a}}$ multistate Markov model $(\mathrm{n}=619)$

\begin{tabular}{lccc}
\hline & Age $\leq 90$ & Age $>90$ & \\
\hline APOE $-\varepsilon 4$ & RR $(95 \%$ CI $)$ & RR $(95 \%$ CI $)$ & n \\
\hline Noncarrier & $\mathbf{2 . 9 3 ( 2 . 1 8 - 3 . 9 2 )}$ & $\mathbf{0 . 4 7}(\mathbf{0 . 2 9}-\mathbf{0 . 7 6})$ & 478 \\
Carrier & $0.68(0.38-1.21)$ & $\mathbf{0 . 1 1}(\mathbf{0 . 0 5}-\mathbf{0 . 2 3})$ & 141
\end{tabular}

Abbreviations: $A P O E-\varepsilon 4=$ apolipoprotein E- $\varepsilon 4$ allele; Carrier $=$ carries at least one $A P O E-\varepsilon 4$ allele; $\mathrm{RR}=$ relative rate

${ }^{\text {a }}$ Breakpoint is age 90

Note: Bold indicates statistically significant results. The relative transition rate $(\mathrm{RR})$ of reversion from MCI to NC vs. progression from MCI to dementia is calculated as the ratio of the transition rate from MCI to NC divided by the transition rate from MCI to dementia. RR $>1$ indicates subgroups with a higher transition rate of reversion from MCI to NC vs. progression from MCI to dementia. $\mathrm{RR}<1$ indicates subgroups with a lower transition rate of reversion from MCI to NC vs. progression from MCI to dementia. 
Table 4: Relative transition rate of reversion from MCI to normal cognition vs. progression from MCI to dementia for education by age and $A P O E-\varepsilon 4$ status using a piecewise-constant ${ }^{\mathrm{a}}$ multistate Markov model $(\mathrm{n}=619)$

\begin{tabular}{|c|c|c|c|c|}
\hline & & \multicolumn{3}{|c|}{ Education } \\
\hline & & $\leq$ High School & Bachelor's Degree & $\geq$ Master's Degree \\
\hline Age & $A P O E-\varepsilon 4$ & RR (95\% CI) & RR $(95 \%$ CI $)$ & RR $(95 \%$ CI $)$ \\
\hline$\leq 90$ & Noncarrier & $1.16(0.49-2.74)$ & $3.00(2.01-4.49)$ & $3.40(2.37-4.87)$ \\
\hline$\leq 90$ & Carrier & $0.27(0.10-0.74)$ & $0.69(0.37-1.30)$ & $0.78(0.42-1.44)$ \\
\hline$>90$ & Noncarrier & $0.19(0.08-0.50)$ & $0.51(0.30-0.87)$ & $0.57(0.33-0.99)$ \\
\hline$>90$ & Carrier & $0.04(0.01-0.14)$ & $0.12(0.05-0.25)$ & $0.13(0.06-0.29)$ \\
\hline
\end{tabular}

Abbreviations: $A P O E-\varepsilon 4=$ apolipoprotein E- $\varepsilon 4$ allele; Carrier $=$ carries at least one $A P O E-\varepsilon 4$ allele; $\mathrm{RR}=$ relative rate

${ }^{\mathrm{a}}$ Breakpoint is age 90

Note: Bold indicates statistically significant results. $R R>1$ indicates subgroups with a higher transition rate of reversion from MCI to NC vs. progression from $\mathrm{MCI}$ to dementia. $\mathrm{RR}<1$ indicates subgroups with a lower transition rate of reversion from $\mathrm{MCI}$ to $\mathrm{NC}$ vs. progression from MCI to dementia. 
Table 5: Relative transition rate of reversion from MCI to normal cognition vs. progression from MCI to dementia for academic performance and written language skills by age and APOE- 4 status using a piecewise-constant ${ }^{\mathrm{a}}$ multistate Markov model

Academic Performance

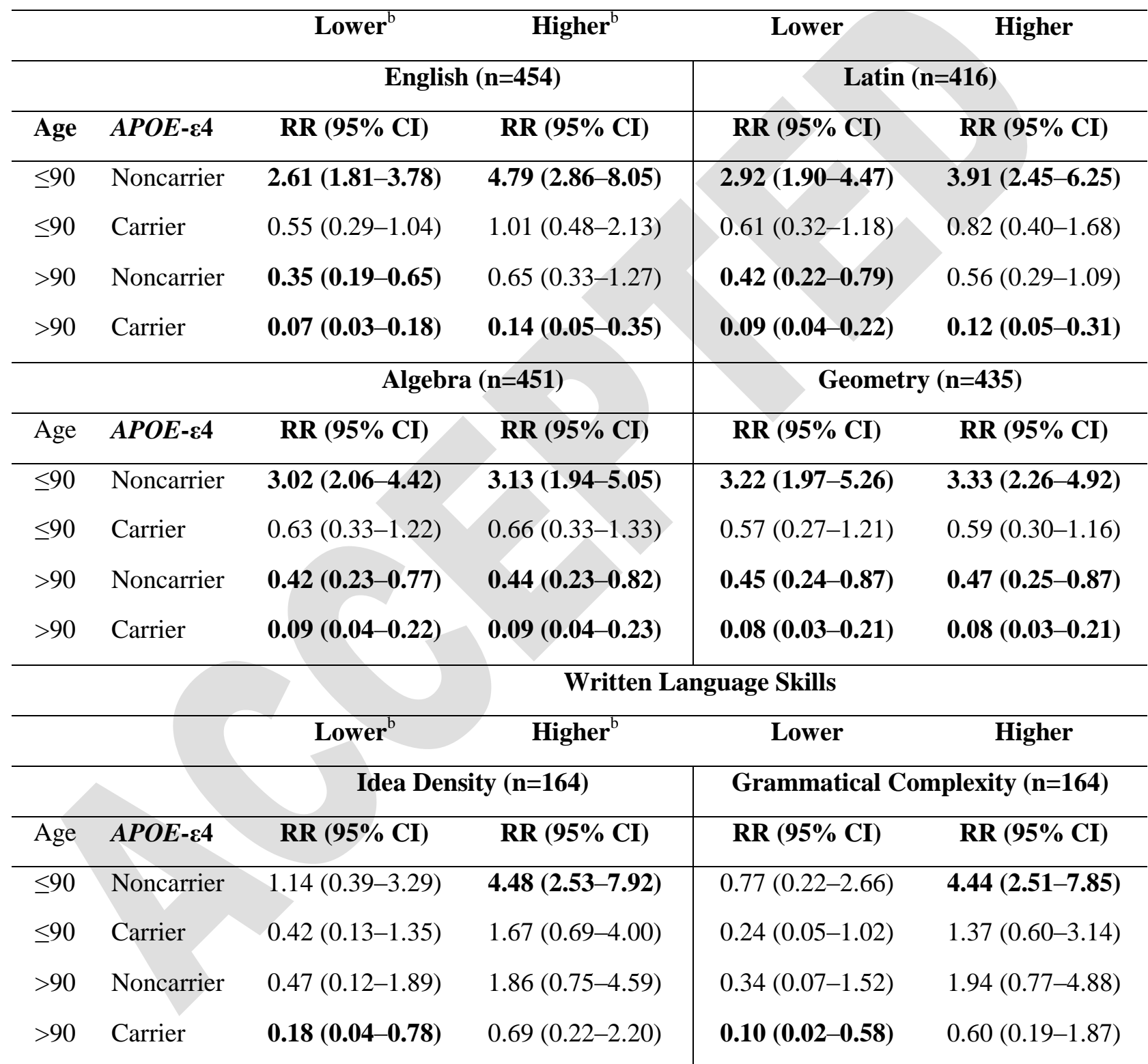

Abbreviations: $A P O E-\varepsilon 4=$ apolipoprotein E- $\varepsilon 4$ allele; Carrier $=$ carries at least one $A P O E-\varepsilon 4$ allele; $\mathrm{RR}=$ relative rate

${ }^{\mathrm{a}}$ Breakpoint is age 90

${ }^{\mathrm{b}}$ Higher academic performance (grade $>90 \%$ ) vs. lower (grade $\leq 90 \%$ ) 
${ }^{c}$ Higher written language skills (quartiles 2 to 4 ) vs. lower (quartile 1)

Note: Bold indicates statistically significant results. RR $>1$ indicates subgroups with a higher transition rate of reversion from MCI to NC vs. progression from MCI to dementia. RR<1 indicates subgroups with a lower transition rate of reversion from MCI to NC vs. progression from MCI to dementia. 
Table 6: The ratio of relative transition rates of reversion from MCI to normal cognition vs. progression to dementia by level of education, academic performance, and written language skills adjusted for age and $A P O E-\varepsilon 4$ status using piecewise-constant ${ }^{\mathrm{a}}$ multistate Markov modelling

\begin{tabular}{|c|c|c|c|}
\hline Predictors & Level & RR Ratio & $95 \% \mathrm{CI}$ \\
\hline \multirow[t]{2}{*}{ Education } & Bachelor's degree vs. $\leq$ High & 2.60 & $1.05-6.45$ \\
\hline & $\geq$ Master's degree vs. $\leq$ High & 2.94 & $1.20-7.22$ \\
\hline \multicolumn{4}{|l|}{ Academic Performance ${ }^{b}$} \\
\hline English & Higher vs. lower & 1.83 & $1.07-3.14$ \\
\hline Latin & Higher vs. lower & 1.34 & $0.80-2.26$ \\
\hline Algebra & Higher vs. lower & 1.04 & $0.63-1.71$ \\
\hline Geometry & Higher vs. lower & 0.97 & $0.57-1.63$ \\
\hline \multicolumn{4}{|l|}{ Written Language } \\
\hline Idea density & Higher vs. lower & 3.93 & $1.30-11.92$ \\
\hline Grammatical complexity & Higher vs. lower & 5.78 & $1.56-21.42$ \\
\hline
\end{tabular}

Abbreviations: $A P O E-\varepsilon 4$ = apolipoprotein $\mathrm{E}-\varepsilon 4$ allele; $\mathrm{CI}=$ confidence interval; $\mathrm{RR}$ ratio = ratio of relative transition rates

${ }^{\text {a }}$ Breakpoint is age 90

${ }^{\mathrm{b}}$ Higher academic performance (grade $>90 \%$ ) vs. lower (grade $\leq 90 \%$ )

${ }^{c}$ Higher written language skills (quartiles 2 to 4 ) vs. lower (quartile 1)

Note:

1. Sample size is based on the number of participants with complete data on characteristics in multivariable analyses: $n=619$ except for academic performance (English $n=454$, Latin $n=416$, algebra $n=451$, geometry $n=435)$ and written language skills $(n=164)$ 
2. Bold indicates statistically significant results. The RR ratio is calculated as the ratio of relative transition rates (reversion from MCI to NC vs. progression to dementia) between two subgroups (e.g., the RR of a higher level of education compared to a lower level of education on reversion vs. progression), reflecting the impact of cognitive reserve indicators on the RR. 
Figure 1: The multistate diagram of a four-state transition model

The nodes represent the three cognitive states and death. A multistate Markov model was used for joint modelling of transitions between cognitive states and death, focusing on reversion from $\mathrm{MCI}$ to NC and progression from MCI to dementia, and considering that death could occur at any time.

Abbreviations: $\mathrm{NC}=$ normal cognition, $\mathrm{MCI}=$ mild cognitive impairment

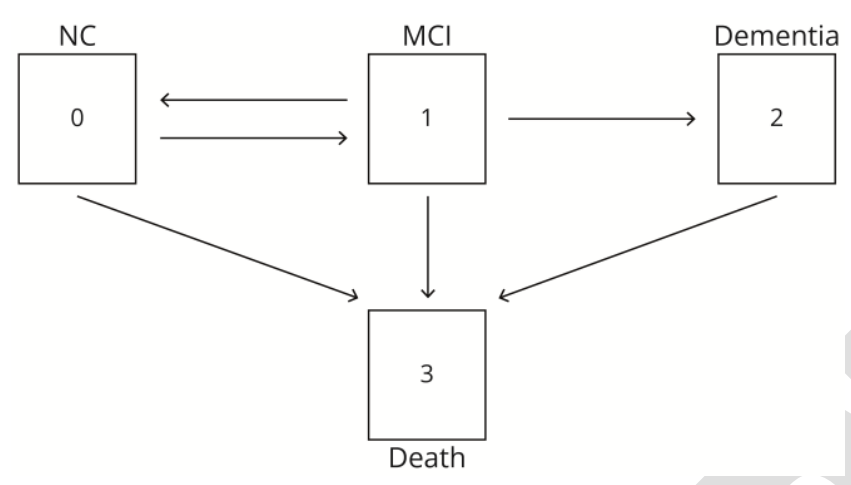




\title{
Neurology
}

\author{
Cognitive Reserve and Mild Cognitive Impairment: Predictors and Rates of Reversion to \\ Intact Cognition vs Progression to Dementia \\ Maryam Iraniparast, Yidan Shi, Ying Wu, et al. \\ Neurology published online February 4, 2022 \\ DOI 10.1212/WNL.0000000000200051
}

This information is current as of February 4, 2022

Updated Information \&

Services

Citations

Subspecialty Collections

Permissions \& Licensing

Reprints including high resolution figures, can be found at: http://n.neurology.org/content/early/2022/02/04/WNL.0000000000200051.f ull

This article has been cited by 1 HighWire-hosted articles: http://n.neurology.org/content/early/2022/02/04/WNL.0000000000200051.f ull\#\#otherarticles

This article, along with others on similar topics, appears in the following collection(s):

All Cognitive Disorders/Dementia

http://n.neurology.org/cgi/collection/all_cognitive_disorders_dementia MCI (mild cognitive impairment)

http://n.neurology.org/cgi/collection/mci_mild_cognitive_impairment

Risk factors in epidemiology

http://n.neurology.org/cgi/collection/risk_factors_in_epidemiology

Information about reproducing this article in parts (figures,tables) or in its entirety can be found online at:

http://www.neurology.org/about/about_the_journal\#permissions

Information about ordering reprints can be found online:

http://n.neurology.org/subscribers/advertise

Neurology ${ }^{\circledR}$ is the official journal of the American Academy of Neurology. Published continuously since 1951, it is now a weekly with 48 issues per year. Copyright Copyright $@ 2022$ The Author(s). Published by Wolters

Kluwer Health, Inc. on behalf of the American Academy of Neurology.. All rights reserved. Print ISSN:

0028-3878. Online ISSN: 1526-632X.

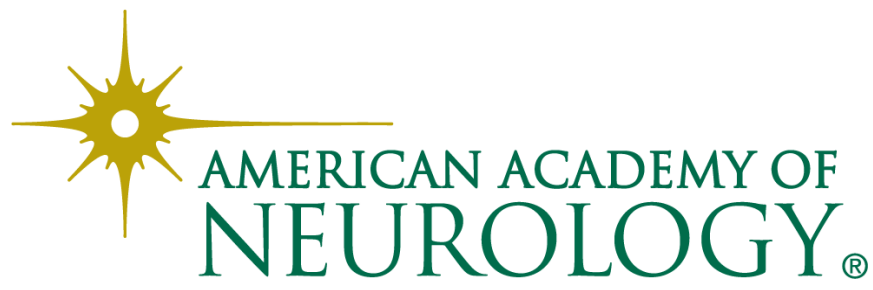

